\title{
Foundations of a Wisdom-Cultivating Pedagogy: Developing Systems Thinking across the University Disciplines
}

\author{
Mark Bracher
}

Citation: Bracher, M. Foundations of a Wisdom-Cultivating Pedagogy: Developing Systems Thinking across the University Disciplines. Philosophies 2021, 6, 73. https://doi.org/10.3390/ philosophies6030073

Academic Editor: Nicholas Maxwell

Received: 26 May 2021

Accepted: 26 August 2021

Published: 1 September 2021

Publisher's Note: MDPI stays neutral with regard to jurisdictional claims in published maps and institutional affiliations.

Copyright: (C) 2021 by the author. Licensee MDPI, Basel, Switzerland. This article is an open access article distributed under the terms and conditions of the Creative Commons Attribution (CC BY) license (https:/ / creativecommons.org/licenses/by/ $4.0 /)$.
English Department, Kent State University, Kent, OH 44242, USA; mbracher@kent.edu

\begin{abstract}
Efforts to educate for wisdom are sorely needed in order to solve humanity's most pressing problems, as explained by philosopher Nicholas Maxwell and psychologist Robert Sternberg, among others. This paper explains that the handful of wisdom pedagogies that have been put forward to date, however, are inadequate for developing the sort of wisdom that can solve our major problems, because they fail to identify and target for development four cognitive functions necessary for wise decision-making. These functions are causal analysis, prospection, social cognition, and metacognition. I show how adequately performing these cognitive functions, which constitute the core of systems thinking, is necessary for solving our most serious global problems, as various systems-thinking experts have also argued. Drawing on recent research on learning and the development of expertise, I explain how the capabilities to perform these functions can be developed by pedagogical methods that help students construct more adequate cognitive models of (i) natural, social, and psychological systems of cause and effect and (ii) the cognitive procedures required to comprehend and effectively intervene in these systems. The basic principles for implementing this wisdom/systems-thinking pedagogy across academic disciplines are explained, and examples from different disciplines are provided.
\end{abstract}

Keywords: wisdom; systems thinking; causal analysis; prospection; social cognition; metacognition; pedagogy; education; global problems

\section{Introduction: Why Try to Educate for Wisdom?}

Wisdom, which I will define as the ability to respond to actual or potential problems with decisions that maximize flourishing for all affected parties, both now and in the future, produces wide-ranging and profound benefits not only for those seemingly rare individuals who possess it-for whom it provides empirically verified social, economic, psychological, and even physical health benefits [1] - but also for the countless other people who are affected by the wise decisions made by such individuals. And conversely, the absence of wisdom in powerful people-and in those who give them power-has produced massive suffering and injustice throughout history. History is replete with unwise decisions by powerful people that have resulted in hundreds of millions of deaths, as well as immeasurable suffering by the living. Decisions concerning military engagements alone offer abundant instances of catastrophic unwisdom, and domestic policies regarding substance abuse, crime, poverty, homelessness, energy, transportation, the environment, and other matters also furnish countless lamentable examples. And now, when the rise of authoritarianism, tribalism, environmental degradation, and climate-change denial, along with wishful and even magical thinking, indicate that wisdom in high places has sunk to a new low, the need for enhancing wisdom is even more pressing. As psychologist Stephanie Thornton observes, "more than ever before we need a population that can make wise decisions as they take direct action, such as voting, or even tweeting" [2] (n.p.).

In response to this urgent need for better decision-making in the public sphere, educators are sounding alarms and calling for a concerted effort to cultivate wisdom through education. American educational psychologist Robert Sternberg and British philosopher 
Nicholas Maxwell have actually been making this case for several decades. Sternberg points out that knowledge and intelligence alone have proven inadequate for solving the world's greatest problems. IQ scores, he notes, have risen approximately 30 points both in the US and globally over the past century, yet this increase in intelligence has not produced solutions to impending disasters such as those involving the environment, nuclear weapons, and population growth, nor has it eliminated intergroup hostilities and their terrible consequences:

Certainly there is no reason to believe that increasing IQs have improved people's or nations' relations with each other. Indeed, today there is more terrorism than at any time in recent memory. In the 1990s, there were more genocides and massacres than at any time since the Second World War. As people became smarter, they became, if anything, less wise and moved further from-rather than closer to- the pursuit of a common good. High IQ with a scarcity of wisdom has brought us a world with the power to finish itself off many times over. [3] (pp. 144, 147)

Maxwell makes a similar point concerning knowledge. Not only has the enormous increase in scientific knowledge failed to solve these problems, it is actually responsible for them: without the technologies and industries that scientific knowledge has made possible, the environmental, nuclear-weapons, and population-growth problems would not exist. The problem, however, is not the existence of such knowledge. The problem, Maxwell explains, is its existence in the absence of wisdom:

If modern science had not come about, none of the global problems would have arisen. But equally, if humanity had possessed wisdom sufficient first, to foresee the likely undesirable consequences of the use of science and technology, and second, to take action to prevent their occurrence, our global problems would not have arisen either. It is the combination of science and technology plus lack of social wisdom that is so deadly. [4] (p. 761)

It is thus unwise for education to continue to focus exclusively on the development of knowledge and intelligence. Something more is needed. Some educators might argue that, at least in higher education, we already educate for more than knowledge and IQ-score intelligence: we teach critical thinking. But while critical thinking is quite valuable and indeed indispensable, it is by itself insufficient to solve our most pressing problems. One reason is that critical thinking can be-and often is-utilized to pursue narrow self-interest, as well as short-sighted and even nefarious goals: there is at present a bevy of critical thinkers working to justify the cruel policies and authoritarian and illegal actions of some of the most powerful people in the US. A second reason is that critical thinking focuses primarily on the validity and truthfulness of arguments, while wisdom, as I will explain shortly, requires an understanding of causality_that is, a grasp of the way things work [5] (p. 69.)

What education needs to do, then, is not simply make people smarter, more knowledgeable, or better critical thinkers; it also needs to help them become wiser. "Wisdom represents a means through which a better, more civilized and peaceful world can be created", Sternberg asserts, and he argues that "society should make it the responsibility of educational systems to facilitate the development of students' wisdom" [6] (pp. 374, 375). Maxwell, arguing for an even more radical change in education, declares, "We need an academic revolution. Universities need to start devoting reason to the task of helping us develop wiser ways of living, wiser institutions, customs, social relations, a wiser world" [4] (p. 755). He argues, further, "that we need to transform academic inquiry so that its basic aim becomes not just to acquire knowledge but rather to seek and promote wisdom" (p. 755). "In order to acquire a bit more social wisdom," he advises, "we need our institutions of learning to be rationally devoted to the job. At present they are not, and that is the underlying source of our current global malaise" (p. 779).

Other educators, such as American University Dean Peter Starr, are adding their voices to the call for wisdom education. Writing in the July 24, 2018 issue of Inside Higher Ed, Starr states: "As hardheaded academics, we tend to be suspicious of the seemingly mushy, 
New Agey concept of wisdom. But in a political and social age that devalues cognitive and moral nuance, ignores the determinative force of cultural difference, and leaves both empathy and cognitive humility in short supply, we have no choice but to consistently, and self-consciously, teach for wisdom" [7] (n.p.)

\section{Can Wisdom Be Taught?}

But can wisdom be taught? Although it has been highly valued and coveted by virtually every society throughout history, it has often been seen in the West, as Starr noted, as a "mushy, New Agey concept" - that is, an undefinable quality that simply emerges organically with age and experience and is therefore unteachable. In recent years, however, many researchers have come, like Aristotle, to see wisdom (Aristotelian phronesis) not as a "mushy, New Agey concept" but rather as a type of expertise- that is, as a set of skills that can be developed and trained. Philosopher Jason Swartwood, for example, argues "that wisdom is the same kind of epistemic achievement as expert decision-making skill in areas such as firefighting" and that wisdom can therefore be developed in the same basic ways as these other expert decision-making skills are [8] (p. 512). Many wisdom researchers today concur: wisdom is a form of expertise, which means that it is a set of skills-such as playing chess, riding a bicycle, playing a musical instrument, or diagnosing a medical problem - and since such skills can be developed and hence taught, it should be possible to teach wisdom as well. This is not to suggest that emotions and values play no role in wisdom. On the contrary, qualities such as compassion, humility, and fairness are central to wisdom. And such qualities, as I will explain, are developed by improved social cognition - that is, enhanced understanding (both implicit and explicit, conscious and unconscious) of other people.

\subsection{The Current State of Wisdom Pedagogy}

So far, however, consensus has been lacking concerning the precise nature of wisdom, the particular skills that constitute it, and the best ways of developing these skills [9]. As a result, only a handful of wisdom-cultivating pedagogies have been reported to date, and these are significantly limited in several consequential ways. First, their respective definitions of wisdom are in various ways unclear or imprecise and hard to operationalize, since they are often formulated, in part at least, in terms of character traits rather than skills. This imprecision contributes to their second, most fundamental problem, which is their failure to adequately identify the set of psychological capabilities that are together both necessary and sufficient to produce wise decisions: some of the proposed capabilities are not necessary for producing wisdom, and the entire sets of nominated capabilities are not by themselves sufficient to produce it, because essential capabilities are lacking from each of these proposed sets. And this deficiency, in turn, contributes to the third and most critical limitation of current wisdom pedagogies: their failure to adequately operationalize wisdom in pedagogical principles and practices that would optimally develop the wisdomconstituting capabilities by engaging students in the kinds of activities that develop these capabilities. That is, the pedagogical strategies do not sufficiently focus on, and the pedagogical practices do not adequately engage students in, the types of activities that are optimal for skill development in general and, more importantly, for wisdom-constituting skills in particular. An effective wisdom pedagogy requires, first, correctly identifying the cognitive functions that are both necessary and sufficient for producing wise decisions, and second, designing pedagogical practices that engage students in activities that develop the cognitive capabilities that perform these functions.

In what follows, I will first provide summaries and critiques of the wisdom definitions, wisdom components, and pedagogical practices of the two most systematic and welldesigned wisdom pedagogies to date. Then, drawing from recent developments in the cognitive science of learning, I will sketch out what I believe promises be a more effective wisdom-cultivating pedagogy. I believe it will be more effective because it more accurately 
identifies, first, the cognitive components of wisdom and second, the pedagogical practices that most effectively exercise and thereby develop these cognitive components.

\subsubsection{Bruya and Ardelt's Pedagogy}

Only the wisdom pedagogy recently developed by Brian Bruya and Monika Ardelt has reported empirical evidence of effectiveness. This pedagogy constitutes a marked advance over previous wisdom pedagogies, in that its practices are derived from a more systematic analysis of wisdom than were those of the previous pedagogies, which tend to rely largely on intuitive adaptations of common pedagogical principles and procedures (see, e.g., [3], p. 151). Thus, in contrast to other wisdom pedagogies, Bruya and Ardelt begin with the important recognition "that wisdom is best conceived not as a kind of knowledge but as a set of capacities" [10] (p. 240). And the basic steps that Bruya and Ardelt take to develop their wisdom pedagogy are also exemplary. They include:

1. Identifying the skills or capabilities that constitute wisdom.

2. Targeting these skills with specific pedagogical practices.

3. Formulating pedagogical practices that engage students in empirically established learning activities-specifically, practice of the skills and encounter with exemplars.

4. Assessing students' learning with empirical measures.

As a result, in all likelihood, of their more systematic approach, empirical measures show this pedagogy producing definite improvements in certain capacities that Bruya and Ardelt claim as components of wisdom. This is an important finding, for as Bruya and Ardelt note, it constitutes the first proof-of-concept for wisdom pedagogy - that is, evidence that it is possible to enhance wisdom through formal instruction in university courses.

Unfortunately, this pedagogy also has significant shortcomings, particularly when viewed in light of the hope that wisdom can help to solve the world's most pressing problems. The most fundamental limitation is the set of capacities that it claims to be constitutive of wisdom. These capacities include the abilities to do the following:

- Think through complex and interconnected ideas.

- Articulate values.

- Develop oneself.

- Self-reflect.

- Sympathetically evaluate the perspectives of others, with the motivation to act toward the good of others ([10], p. 249).

While each of these abilities may certainly contribute to wise decisions, it is not selfevident that they are either individually necessary or collectively sufficient to produce wisdom as defined above. One reason is vagueness, especially regarding the first, the ability to "think through complex and interconnected ideas". What kind of complex and interconnected ideas and what kind of thinking are involved in wisdom? Greater specificity and precision are needed.

A more fundamental problem is the process by which this set of capacities was derived. Rather than beginning with a precise definition of the particular type of expertise or ability that they take wisdom to be and then proceeding to analyze this ability into its component capacities, Bruya and Ardelt instead derive the putative wisdom-producing capacities by "condensing" the capacities that five previously developed wisdom pedagogies-none of which was shown to be effective- took to be constitutive of wisdom. In the absence of a definition of the construct of wisdom (an absence that Bruya and Ardelt explicitly acknowledge [10], p. 249), there is no basis for determining the adequacy of the set of capacities proposed as constitutive of wisdom.

A final reason to doubt the adequacy of this proposed set of capacities for solving global problems is the authors' explicitly stated focus on what they (and some other researchers as well, e.g., Staudinger [11]) call personal wisdom rather than general wisdom. Personal wisdom, as operationalized in the capacities they propose as constitutive of it, in- 
volves self-awareness and self-cultivation more than the cognitive skills that would enable one to make wise policy decisions. This emphasis is also clear from their course's central learning objectives: understanding and self-development, which "are stated explicitly on the first day and are reinforced implicitly in how the course is conducted" [10] (p. 354). The limited efficacy of this pedagogy for preparing students to respond wisely to social problems is also indicated by the empirical findings reported by Bruya and Ardelt, in which compassion was the only dimension of wisdom in which the course produced an increase: average scores on the cognitive and reflective dimensions did not increase (though the cognitive scores did avoid the decrease shown by the control classes [12], p. 110).

\subsubsection{Sternberg's Pedagogy}

In contrast to Bruya and Ardelt's pedagogy, the pedagogy developed by Sternberg and colleagues for an eighth-grade US history course aims to develop decision-making skills that lead to wise policy decisions rather than personal virtue and well-being. One of its strengths is that it is starts with a definition of wisdom, originally proposed by Sternberg in his "balance theory" of wisdom [13], that is both precise and comprehensive:

Wisdom is defined here as the application of intelligence, creativity, and knowledge as mediated by values toward the achievement of a common good through a balance among ( $a$ ) intrapersonal, (b) interpersonal, and (c) extrapersonal interests, over the (a) short-and ( $b$ ) long-terms, in order to achieve a balance among (a) adaptation to existing environments, (b) shaping of existing environments, and (c) selection of new environments. [3] (p. 145)

Central to this notion of wisdom, Sternberg emphasizes, is the seeking of a common good: "If one's motivations are to maximize certain people's interests and minimize other people's, wisdom is not involved" (p. 146). Also important is the stipulation that this good be long-term and not just immediate. And it is clearly the case that actions that meet these two criteria will involve adapting to, altering, and/or switching environments.

I take Sternberg's definition to be not only fundamentally sound and accurate, but also one of the best that has been offered to date. The definition is less than optimal, however, as a basis for designing a wisdom-cultivating pedagogy. One limitation is its lack of parsimony: it includes elements that may be entailed by wise decisions but that are not essential to it. This is the case for the stipulation that wisdom is "the application of intelligence, creativity, and knowledge as mediated by values toward the achievement of a common good," a potentially confusing proviso that is also unnecessary, since the declaration that wisdom seeks a common good would suffice. The same is true of the statement that wisdom involves a balance among intrapersonal, interpersonal, and extrapersonal interests, which is an unnecessary and potentially complicating provision because such a balance is entailed by the seeking of a common good. And the proviso that there must be a balance among adapting to, altering, and seeking a new environment not only confuses an entailment of wisdom with a necessary factor, it also mistakenly assumes that there must be a balance among these three modes of action, when in fact the best way to achieve a common good often does not involve all three of these modes of response to an environment.

These limitations of the definition become evident when we move to the pedagogical procedures that Sternberg and colleagues designed. Indeed, they appear to acknowledge the difficulty the definition poses for operationalization, but nonetheless believe that it does not constitute an insurmountable obstacle, stating: "Although it is a complex model accounting for real behaviors in real contexts, it is possible to apply the theory in a concrete, real-world setting" [3] (pp. 150, 151). Perhaps. But there is a significant disconnect between the definition and the pedagogical principles and procedures that are proposed as the core of this wisdom pedagogy. Sternberg et al. begin the transition from definition to pedagogy with the crucial question: "What then are the processes underlying wise thinking that students have to acquire, and how can they be introduced into the classroom?" (p. 151). But although they pose this question, they do not really answer it. And as a result of this failure to identify the cognitive functions that produce wise decisions, the pedagogical 
principles and procedures they propose lack internal coherence and possess only tenuous connections with wisdom as Sternberg defines it.

The "principles of teaching for wisdom derived from the balance theory of wisdom" [13] (p. 169) include helping students learn the following:

1. That conventional abilities are not enough for a satisfying life.

2. How wisdom is critical for a satisfying life.

3. The usefulness of interdependence-a rising tide raises all ships.

4. What wise actions are, by modeling them for students.

5. That wise judgments and decisions exist, by reading about them.

6. Their own interests, those of other people, and those of institutions.

7. How to balance their own interests, those of other people, and those of institutions.

8. That the means by which the end is obtained matters.

9. The option of choosing among adaptation, shaping, and selection of environments.

10. How to form, critique, and integrate their own values in their thinking.

11. How to think dialectically, realizing that both questions and answers evolve over time.

12. How to think dialogically, understanding interests and ideas from multiple points of view.

13. How to seek the common good, where everyone wins, not just those one identifies with.

14. That wisdom is rewarding.

15. How to monitor events in their lives and their own thought processes about these events.

16. The importance of inoculating oneself against the pressures of unbalanced selfinterests and small-group interests [3] (pp. 169, 170).

This list, while clearly related to the balance-theory definition of wisdom, constitutes not so much a coherent pedagogical strategy as a collection of potentially useful learning objectives. And even more problematically, as I will explain shortly, it omits the cognitive functions that are necessary for solving the world's greatest problems. As a result, students could meet all of these learning objectives and still fail to make wise decisions, especially regarding the sorts of global problems that Sternberg argues wisdom can help to solve.

Following his presentation of these principles, Sternberg proposes "six procedures to follow in teaching for wisdom":

1. Have students read classic works of literature and philosophy (whether Western or otherwise) to learn and reflect on the wisdom of the sages.

2. Engage students in discussions of the lessons they have learned from these works and how these lessons can be applied to their own lives and the lives of others.

3. Encourage students not only to study "truth" but also to develop their own values, through reflective thinking.

4. Place an increased emphasis on critical, creative, and practical thinking in the service of good ends-that benefit others as well as oneself.

5. Encourage students to think about how almost any topic they study might be used for better or worse ends, and about how important that final end is.

6. Be a role model of wisdom [13] (p. 170).

These procedures may, as Sternberg and colleagues hope, "help teachers systematically and frequently implement sound teaching procedures that foster wise thinking" [3] (p. 151), and their discussion of particular practices implementing these procedures includes some valuable pedagogical suggestions. But as they themselves acknowledge, "many of these procedures are already in use by classroom teachers" (p. 151), and more problematically, the procedures, like the pedagogical principles proposed, fail to identify, and thus show no evidence of effectively engaging and developing, the key cognitive functions that must be performed in order to produce wise decisions. Thus, not surprisingly perhaps, an assess- 
ment of the learning outcomes of this pedagogy failed to find significant improvements in students' decision-making ([14] cited in [9] (p. 253)).

In addition, Sternberg's emphasis on values as an integral part of wise thinking presents a problem: which values should guide decision-making? This issue presents a dilemma for any wisdom pedagogy. A pedagogy that simply encourages students to reflect on, or develop, their own values could well result in values inconsistent with, or even antithetical to, the common good-for example, racist, sexist, homophobic, or nationalist values. On the other hand, a pedagogy that worked to inculcate certain values would immediately become authoritarian and thus ethically problematic as well as, in all likelihood, less than optimally effective. I will argue that these issues can be resolved by training in systems thinking, which enables students to understand more clearly and comprehensively how the world works and, in doing so, reveals self-interest to entail pursuit of the common good, as well as compassion, humility, and fairness.

\section{Cognitive Components of Wisdom}

The failure to adequately identify the key psychological components wisdom, which is crucial for designing a successful wisdom pedagogy, thus severely limits the effectiveness of such efforts. This problem is not limited to just the wisdom pedagogies; it characterizes virtually all wisdom research to date, as is evident from the results of a review of the scientific literature on wisdom. This study found five wisdom-constituting abilities identified by at least half of the 24 published papers that were examined:

1. Social decision making and pragmatic knowledge of life, which relates to social reasoning, ability to give good advice, life knowledge, and life skills.

2. Prosocial attitudes and behaviors, which include empathy, compassion, warmth, altruism, and a sense of fairness.

3. Reflection and self-understanding, which relates to introspection, insight, intuition, and self-knowledge and awareness.

4. Acknowledgment of and coping effectively with uncertainty.

5. Emotional homeostasis, which relates to affect regulation and self-control [15] (p. 1256).

While these five cognitive functions point to key components of wisdom, they are too vague and imprecise to serve as a basis for constructing an effective wisdom pedagogy. "Social decision making and pragmatic knowledge of life," in particular, verges on the tautological and is so vague and general as to be unoperationalizable. What we need to know is: what specific cognitive functions are required for good decision making, and what specific cognitive structures constitute pragmatic knowledge? What is needed is a more functionalist approach, one that would answer the question, what is the set of cognitive functions that must be performed in order to produce optimal responses to global problems of the sort identified by Sternberg, Maxwell, Starr, and others?

Psychologist and wisdom researcher Igor Grossmann and colleagues have provided such a functionalist model by identifying and synthesizing cognitive functions found in multiple conceptual models of wisdom. The key cognitive components of this synthesized model include the following:

1. Seeking others' perspectives and seeing the broader context.

2. Integrating different perspectives.

3. Recognizing uncertainty and the possibility of change in the world.

4. Intellectual humility or recognition of limits of one's own knowledge [16,17].

These four cognitive functions offer a foundation for operationalizing wisdom for education. But they too suffer from imprecision and, more importantly, they are by themselves insufficient for making wise decisions of the sort needed to solve the world's major problems: one could be exceedingly humble (\#4), profoundly aware of uncertainty and change (\#3), seek different perspectives and be acutely aware of the broad, even cosmic contexts (\#1), integrate all the perspectives (\#2), and still be utterly clueless about how to solve a problem. 


\section{Systems Thinking/Causal Reasoning as the Core of Wisdom}

Beginning with a more adequate functionalist definition will enable identification of the specific cognitive functions that are necessary and sufficient to produce wise decisionsa move that, as the question posed by Sternberg and colleagues suggests, is a prerequisite for identifying pedagogical practices that develop the cognitive capabilities necessary to perform these wisdom-producing functions. I therefore begin with the definition of wisdom presented at the beginning of this article: wisdom is the ability to respond to actual or potential problems with decisions that maximize flourishing for all affected parties, both now and in the future. This definition of wisdom is essentially a condensed version of the definition offered by Maxwell, which states that wisdom is "the desire, the active endeavor, and the capacity to discover and achieve what is desirable and of value in life, both for oneself and for others" [4] (p. 754). At the end of the day, however, my main concern in this article is not to convince anyone to adopt a particular definition of wisdom or to argue for or against any particular wisdom pedagogy. Rather, my primary argument is that systems thinking as I will describe it, whether or not one thinks it has any connection with wisdom, is necessary for solving the world's greatest problems, and that systems-thinking training across the disciplines can help to meet this need.

Defining wisdom as the ability to respond to problems with decisions that maximize flourishing for all affected parties, both now and in the future, enables us to proceed systematically to develop a set of pedagogical practices for developing this ability by taking the following steps:

1. Identifying the specific cognitive functions through which such decisions are produced.

2. Identifying the processes by which the cognitive capabilities for performing these functions are developed.

3. Formulating pedagogical practices that optimally engage these formative processes and thereby develop the capabilities needed to perform the wisdom-producing cognitive functions.

The first step, then, is to ask: what cognitive tasks does one have to perform in order to maximize flourishing for all affected parties, both now and in the future? I propose that the core cognitive function is causal understanding, and that the two basic tasks that must be accomplished for wise decision-making are "backward" causal reasoning, or causal analysis, and "forward" causal reasoning, or prospection and strategic planning. As psychologists Steven Sloman and Philip Fernbach explain, "You need to engage in causal reasoning to identify the problem and to figure out what to do about it. We reason both forward and backward. Forward reasoning is thinking about how causes produce effects. We use it to predict the future. Reasoning backwards is reasoning from effects to causes. Doctors use it to diagnose the cause of symptoms and mechanics do it to diagnose what's wrong with your car" $[18]$ (pp. 57, 58). Therefore "causal principles," as Sloman observes, " ... are the most reliable bases for judgment and action we have ... Causality ... tells us ... what to expect when we take action ... Causal relations tell you how you get there from here" [5] (pp. 19, 52, 25).

These two basic causal-reasoning tasks have been almost totally ignored by wisdom research to date. Their importance has been recognized, however, by the field of systems thinking, which emphasizes backward causal reasoning, or systems analysis-that is, the systematic identification of all types and levels of causes of a problem-and prospection and strategic planning, or forward causal reasoning, as essential for problem-solving [19,20]. Systems thinking is especially crucial for addressing the most pressing problems confronting humanity, including poverty, inequality, war, terrorism, nationalism, racism, classism, environmental degradation, species extinction, and climate change [19-24]. A fundamental common feature of these problems is their systemic nature: they are the result not of simple causes that can be identified and addressed in isolation from other causes, but rather of multiple, complex networks of causality (i.e., systems) interacting with each other. Systems are assemblages of parts that exist in causal relationships with each other, and sys- 
tems thinking involves the comprehensive mapping of all types and levels of these causes, followed by the identification of interventions in this causal network that will achieve a desired result. "All real systems are causal," as Fieguth puts it [22] (p. 50)_-"unitary set[s] of variables interconnected by causal relations," in Mella's words [25] (p. 22)—and systems thinking is a process of "always try[ing] to identify the causes," always "searching for the causal chains" [25] (pp. 25, 12). Thus wisdom, or optimal problem-solving, whether in one's personal life, in one's job, or in the public sphere, requires highly developed capabilities of causal analysis and prospection, the core functions of systems thinking.

\subsection{Backward Causal Reasoning: Causal Analysis, or System Mapping}

The first step of systems thinking, system mapping, is crucial for solving a problem because the causes of a problem are points of possible intervention: any solution to, or amelioration of, a problem must involve eliminating, reducing, or counteracting one or more of its causes. And since most serious problems have multiple causes, an effective response requires cognizance of the full system of causes, including hidden causes, that is producing it. Most importantly, such system mapping requires identifying the role of root causes such as social systems, material and geographical systems, technological systems, and the ideological and cognitive systems that both produce and are produced by these social, material, and technological systems. As the systems-thinking expert Piero Mella explains, instead of simply addressing the symptoms of a problem, "system thinking favors and accelerates the search for the definitive solution [which] almost never derives from variables directly connected to the symptom but often from 'distant' variables, linked to causal chains and loops that must be accurately identified and described" [25] (pp. 212, 231). Failure to recognize significant causes-especially root causes such as social systems, natural systems, and systems of thought-is a major reason that attempted solutions often fail.

To appreciate the importance of adequate causal analysis for wise decision-making and problem-solving in the public sphere, it is sufficient to recall disasters that have resulted from the failure to recognize key causes of a problem. Consider, for example, all the prescientific efforts to prevent disease, earthquakes, floods, droughts, crop failures, and so on by appealing to supernatural beings that were thought to be the immediate cause of these problems. These efforts, which included not only expensive rituals, institutions, and edifices but also terrible practices of human exploitation and even human sacrifice, failed because they were based on a faulty causal understanding, one that attributed these phenomena to supernatural agents-as well as, oftentimes, to human misdeeds that were believed to have caused these gods to cause the human disasters. And although in our day science, which is devoted to the systematic identification of causes, has succeeded in uncovering the true causes of these phenomena and thus reducing, if not totally eliminating, efforts to counteract false causes in these cases, there remain domains in which large segments of humanity still operate in ignorance-or denial — of the key causes of problems. Climate change is a prime example: many people in the US still deny, ignore, or discount the causal role that human activities and systems have played and are continuing to play in global warming. Less obvious, but more widespread, is the failure to identify and address key causes of problematic human behaviors (e.g., substance abuse, crime, violence, war, terrorism, imperialism, fascism) and life outcomes (e.g., inequality, poverty, homelessness, unemployment, incarceration). Only recently, for example, has a general awareness begun to emerge regarding the multiple causal forces operating in systemic racism to oppress Black people and causing them to be disproportionately impoverished and incarcerated.

Identifying the role of root causes such as social and economic systems, material and geographical systems, and the cognitive and neurological systems that both produce and are produced by these social and material systems is no simple task, and without training, such mapping is not only not automatic but also exceedingly hard to adequately execute. We tend to focus on one or two immediate and obvious causes and ignore the more distal and root causes of these immediate causes. Failure to recognize significant 
causes-especially root causes such as social systems, natural systems, and systems of thought-is a major reason that attempted solutions often fail. And these causes often escape recognition, because they are intangible or spatially or temporally imperceptibly large or small [5] (pp. 72-74).

\subsection{Forward Causal Reasoning: Prospection and Strategic Planning}

Prospection, or forward causal reasoning, the second key cognitive function in systems thinking, involves foreseeing the consequences of possible responses to a problem, which is essential for effective strategic planning. After mapping the causes of a problem, one must identify possible interventions in the system of causes and foresee the likely consequencesboth intended and unintended, immediate and long-term, for all parties involved_of each possible intervention, in order to identify the intervention that would most probably maximize the benefits and minimize the harm for all parties, now and in the future. As Mella declares, "Deciding means identifying and evaluating the various alternatives ... that take into account the results that each will allow us to obtain. We must judge an action on the basis of its global effects and long-term effects" [25] (pp. 201, 269, 270).

Like inadequate causal analysis, lack of adequate prospection often results in failure to solve a problem. In addition to resulting in solutions that fail to attain their goal, faulty prospection can lead to actions that, in attaining their goal, also cause serious unintended negative consequences, for other parties and/or oneself, in the present and/or in the future. As Maxwell notes, "almost all the grave global problems that threaten our future have arisen because we have failed to anticipate undesirable consequences of major new social endeavors, made possible by science and technology" [4] (p. 366). A prime example is the centuries-long environmental destruction that has resulted from various large-scale collective activities deriving from innovations that promised, and in most cases delivered, significant improvements in human well-being. Such activities include the deforestation caused by the clearing of land for agriculture and by the harvesting of trees for fuel and construction, the depletion of aquifers and the destruction of ecosystems caused by the construction of dams and massive irrigation systems, and the disruptions of ecosystems and pollution of water caused by mining and drilling operations, as well as the human exploitation and environmental pollution caused by industrialization, which was itself made possible by a laissez-faire capitalist economic system enabled and legitimized by a Social-Darwinist mindset.

Causal analysis and prospection thus constitute the core of wise decision-making. As noted above, taken together they constitute systems thinking, which involves viewing any given phenomenon in relation to all its causes, past and present, and all its possible consequences, direct and indirect, present and future. If one rigorously and comprehensively performs these two systems-thinking functions, then one will produce a wise response to a problem. This is not to say that the adequate performance of these two functions is always an easy task. Indeed, it is often quite difficult, and in some cases impossible. But the better we perform these two tasks, the more likely it is that our actions will produce more benefits and fewer harms for all parties, now and in the future.

\subsection{Social Cognition: Understanding the Causes of People's Behavior and Character}

Two additional cognitive capabilities also play important roles in systems thinking and wisdom. These are social cognition and metacognition. Social cognition, the process of understanding other people, includes understanding the causes of their behaviors, which is a crucial subcomponent of causal analysis and strategic planning. In attempting to solve a problem, it is essential to understand the root causes of the needs, motives, and perceptions of (a) the people who may be causing the problem, (b) the people who are being affected by the problem, (c) the people who would be affected by actions taken to solve the problem, and (d) the people whose action or acquiescence is needed in order to implement a particular response to the problem. Such understanding is necessary in order to be able to (a) choose solutions that eliminate or counteract the causes of the problem-causing 
behaviors and (b) anticipate the respective needs and behaviors that the various solutions might cause in each affected party.

\subsubsection{Understanding the Causes of Behavior}

Most importantly, social cognition involves understanding the causes of other people's behaviors, and thus is a crucial subcomponent of systems analysis. These causes include, first, the causes of problem-causing behaviors, such as substance abuse, crime, violence, terrorism, and so on. The most obvious causes of such behaviors are the characters or personalities of the persons engaging in these behaviors. And accordingly, the most common attempted solutions to such problematic behaviors involve efforts to eliminate or contain the persons engaging in them. Such efforts are central to the "wars" on crime, drugs, and terrorism. Unfortunately, such attempted solutions often fail because they ignore more fundamental, less visible causes of the problematic behaviors. First of all, they often ignore the situation or circumstances that, along with the person's character, also constitute a key and necessary cause of the behavior. As the fundamental principle of social psychology puts it, a person's behavior is caused not simply by the person's character but rather by the person's character plus the person's situation. Criminal behavior, for example, takes place not just when a person has a motive or impulse to commit the act, but when a person with a motive also has the means and opportunity to do so. Hence one way to prevent crimes is to deprive people, especially those with the motive, of the means and opportunity to commit the criminal act-for example, locking doors to prevent theft and destroying drugs to prevent drug trafficking. In such instances, the role of situation is obvious when pointed out. In many cases, however, the situational causes of a behavior are not obvious to observers. We often do not fully know the circumstances that even the people we are closest too are dealing with. And when it comes to strangers, we are often completely ignorant of the situations that are confronting them. The role of situation in causing behavior is systematically overlooked, however, even when that role is not invisible but obvious. Indeed, this blindness to the causal role of situations is so widespread and problematic that it has been given a name by psychologists: the Fundamental Attribution Error.

\subsubsection{Understanding the Causes of Character}

And there is yet another crucial level of causation of behavior that is even deeper and more often ignored than the situation. This is the level of the formative causes of a person's deep motives and character traits. While most people will acknowledge at least some situational causes of bad behavior (e.g., "gun-to-the head" situations in which a decent person is forced to commit a crime), it is generally assumed that people themselves are solely responsible for their good or bad character. Despite the fact that people's characters are determined by two factors, genes and environment, that they do not choose and cannot in the first instance control, these causes are frequently ignored in dealing with social problems involving "bad" people, such as bigots, addicts, criminals, terrorists, and so on. Rather than addressing these root causes of bad character, and hence also of bad behavior, attempts to solve social problems involving bad behavior often focus on excluding, containing, or even eliminating the "bad actors" engaging in the behavior. Such responses are not only suboptimal solutions, they are often frequently counterproductive. The War on Drugs, for example, has concentrated on identifying, capturing, and incarcerating the producers, distributors, and consumers of illegal substances, all of whom are thought to be abnormal, immoral people, rather than on identifying and addressing the causes of their supposed immorality, such as lack of recognition and other means of identity support [26]. And this effort to reduce substance abuse is now widely recognized as having been largely unsuccessful. Similarly, the War on Terrorism has focused on identifying and killing or capturing terrorists rather than on identifying and addressing the root causes of their becoming terrorists - which, include environmental factors that variously form, threaten, and support their identities. And the War on Terrorism has likewise been less than optimally effective, 
resulting in hundreds of thousands of deaths—and more American deaths than 9/11—and fueling the formation of ISIS, a result that experts warned of before the US invasion of Iraq. Thus, the failure to recognize the root, situational causes of people's problematic behaviors and of their toxic character traits that are also causes of these problematic behaviors results in suboptimal responses to the problems.

\subsubsection{Social Cognition and Prospection}

Social cognition is also essential for prospection, insofar as prospection involves foreseeing how other people will respond to the various courses of action that are possible. Government policies often founder as a result of poor social cognition in prospection. The US invasion of Iraq, part of the War on Terrorism, offers a striking example of a catastrophic failure of prospection resulting from disastrously poor social cognition, in the form of predictions that Iraqi citizens would welcome US troops and that the war would be over in a few months, with the US in possession of Iraqi oil. Social scientists and diplomats with better social cognition warned that the invasion would produce counterproductive consequences, including fueling the flames of radical Islamic fundamentalism, and the emergence of ISIS in the aftermath of the invasion proved them right.

Adequate social cognition is thus essential for an effective response to any social problem. Other people's behaviors, and hence their deep needs, motives, and character traits, are both significant causes of social problems, and they also play major roles in determining the consequences of attempted solutions to such problems. Inadequate social cognition in either trouble-shooting or prospection can thus doom a response to failure. A systems approach to social cognition is crucial: adequate social cognition involves recognizing individuals as components of multiple systems-social, cultural, economic, and natural-and as themselves complex systems composed of multiple needs, motives, capabilities, and vulnerabilities. An inadequate grasp of any of these systems-intrapersonal, interpersonal, or extra-personal-will result in deficient social cognition and hence in suboptimal responses to social problems.

\subsubsection{Social Cognition and Human Interconnection}

Adequate social cognition also includes recognizing the various ways in which everyone is interconnected with, interdependent with, and fundamentally the same as all other humans, and such recognition requires a systems perspective. The most obviously systemic form of interconnectedness is existential: we all depend on other humans for our very existence and survival - that is, for the production and distribution of our food, clothing, and shelter, not to mention the complex technologies that we in the post-industrial world have come to rely on. We are dependent on the work of countless other individuals at every moment in our lives, and we simply could not exist without their direct and indirect contributions to our lives.

A second form of interconnectedness is neurological. We humans are hardwired to resonate emotionally with others and to infer their intentions from their actions and expressions. Certain systems in our brains simulate the subjective states of others whom we are watching or even just reading about. These systems include mirror neurons-that is, neurons that fire both when we ourselves engage in an action and when we observe, hear about, or read about another person engaging in that action. Thus, rather than being independent, autonomous, self-enclosed entities, individuals are neurologically bound to each other, interconnected in a kind of neural wi-fi system, and this interconnection has profound effects on our thinking, our feeling, and our behavior, as has been documented by numerous studies of the influences of social norms, peers, and authority figures. Rather than being independent, self-sufficient monads, individuals are more like nodes in a network of individuals, components of a social system.

The fact that we are all fundamentally alike in this and other ways constitutes a third level of connectedness. This is the ontological level: as members of the same species, we all share the same form of being. Underneath all our non-trivial and sometimes 
monumental differences, we all have the same basic needs (psychological as well as physical), vulnerabilities (psychological as well as physical), and capabilities (psychological and physical). And on the basis of these universal human features, we also have more specific points of similarity or sameness with probably most other individuals on the planet, whether these be common feelings, experiences, group memberships, demographic categories, or social or familial roles or positions (e.g., parent, child, sibling).

\subsubsection{Social Cognition and Human Duality}

Adequate social cognition requires constant awareness of this four-fold solidarity that one has with all other humans: contingent, ontological, neurological, and existential. And it also requires understanding and awareness of our universally human dual nature. All humans have two motivational systems. We have what psychologist Jennifer Crocker calls an "eco-system," which has "compassionate goals" and which aims, like wisdom as we are defining it, "to contribute to the well-being of other people". And we also have an "egosystem", which aims to protect and enhance one's self-image, often in disregard of other people or even at their expense [27]. Knowledge and awareness of the ego-system and how it operates automatically, and in ways that undermine wisdom, is crucial for wise decisionmaking. Such awareness and vigilance are especially important when interpersonal or intergroup conflicts are involved, because when people feel threatened, either physically or psychologically, they can easily lose all sense of connectedness with the threatening party and respond in ways that precipitate "a cascade of unintended negative consequences for both themselves and others" [27] (p. 230). In contrast, when we retain awareness of one or more forms of our solidarity with others-our eco-system-we operate with greater humility, compassion, and gratitude, recognizing that without them, we could not exist. As the African philosophical notion of ubuntu recognizes, "I am because you are". This systems-thinking recognition logically entails the commitment to the common good that is crucial for wisdom.

\subsubsection{Systems Thinking and the Common Good}

Rigorous systems thinking is thus not only necessary but also sufficient for wise decisions: it entails not only an understanding of all significant causes of a problem and all the consequences of possible courses of action that might be taken to resolve the problem; it also entails commitment to the common good. Commitment to the common good results from the systems-thinking recognition, first, that all other people are ultimately part of us, neurologically, ontologically, existentially, and contingently. This means that even acting solely on the basis of self-interest entails acting for the well-being of all other people. As the Dalai Lama put it, "It is important that when pursing our own self-interest we should be 'wise selfish' and not 'foolish selfish'. Being foolish selfish means pursuing our own interests in a narrow, shortsighted way. Being wise selfish means taking a broader view and recognizing that our own long-term individual interest lies in the welfare of everyone. Being wise selfish means being compassionate" [28] (n. p.).

\subsubsection{Systems Thinking and the Elimination of Blame}

Rigorous causal analysis also contributes to commitment to the common good by revealing that no one is ultimately deserving of either praise or blame, since all people, including us ourselves, are ultimately constructed by forces beyond our control. We typically assume that certain groups of people who are suffering deserve their suffering, because they have either done bad things or have failed to do everything they could have to avoid their suffering. A rigorous system thinking, however, precludes blame. As the systems-thinking pioneer Peter Senge observes, "there is no blame" in systems thinking [29] (p. 67), because systems thinking recognizes that all behaviors, and all people who engage in behaviors, are the products of a complex network of causes and effects. Systems thinking thus reveals indifference toward the suffering of any individual or group, no matter how bad the persons may be, as not only suboptimal but also ultimately unjust, insofar as it is 
unfair to blame people for being "bad", when they did not choose, or cause themselves, to be bad.

\subsubsection{Systems Thinking and the Elimination of Radically Free Will}

People tend to invoke the notion of free will in such cases, arguing that everyone has free will and therefore could have chosen to do otherwise than they did. But the idea of a radically free will of this sort has been debunked by psychologists, philosophers, and neuroscientists alike. As the psychologists Michael Gill and Stephanie Cerce observe, while everyone may have free will in the sense of not being physically prevented from doing otherwise, physical freedom does not entail behavioral freedom. Gill and Cerce point out that before blaming people for their bad behavior on the grounds that they have "free will" to do otherwise, we need to ask, "Did they will to have the will that they have?" [30]. The answer is of course no. As philosopher Bruce Waller observes, "whether I am vile or virtuous, I am not so by my own making" [31] (p. 27). Even if we become bad or good as a result of choosing to become such, we deserve no ultimate blame or credit, because we did not make the "we" that made the choice to become bad or good. As the philosopher Thomas Nagel puts it, "how can one be responsible even for the stripped down acts of will itself, if they are the product of antecedent circumstances outside of the will's control?" (qtd. in [31], p. 22). In addition to such undermining of the notion of free will by logic, neurological evidence also refutes claims for a morally responsible free will. As neuroscientist Sam Harris explains,

Some moments before you are aware of what you will do next-a time in which you subjectively appear to have complete freedom to behave however you please-your brain has already determined what you will do. I, as the conscious witness of my experience, no more initiate events in my prefrontal cortex than I cause my heart to beat. I cannot decide what I will next think or intend until a thought or intention arises. What will my next mental state be? I do not know-it just happens. Where is the freedom in that? ... How can we be "free" as conscious agents if everything that we consciously intend is caused by events in our brain that we do not intend and of which we are entirely unaware? We can't. [32] (pp. 9, 25, 26)

Furthermore, as Harris observes,

You have not built your mind. And in moments when you seem to build it-when you make an effort to change yourself, to acquire knowledge, or to perfect a skill - the only tools at your disposal are those that you have inherited from moments past. Choices, efforts, intentions, and reasoning influence our behavior-but they are themselves part of a chain of causes that precede conscious awareness and over which we exert no ultimate control. My choices matter, ... but I cannot choose what I choose. And if it ever appears that I do-for instance, after going back and forth between two options-I do not choose to choose what I choose. There is a regress here that always ends in darkness. [32] (p. 39)

This recognition of the illusory nature of free will leads to a mitigation of blame, which produces, as Gill's empirical studies and those of Bracher et al. [33] demonstrate, a corresponding increase in compassion. Recognizing that no one is ultimately to blame for their bad actions or character leads, ultimately, to the Buddhist recognition that no one deserves to suffer; this systems understanding of the root causes of human character and behavior eliminates anger, hatred, and retribution as motives and thus redirects attempts to solve the problem away from the problem-causing persons and toward the systemic causes of these persons' problematic needs, motives, and character traits [34,35].

\subsection{Metacognition: Monitoring and Directing One's Own Causal Reasoning}

A fourth cognitive capability, metacognition, while not an integral component of wise decision-making, is a valuable and often necessary ancillary [21]. Metacognition comprises the understanding, awareness, monitoring, and directing of one's own cognitive processes. If one's causal analysis and prospection, including their social-cognition elements, are 
flawless, then metacognition is not needed. But since such perfection rarely if ever exists, metacognition is usually a very valuable asset. Metacognition for wisdom requires, first, an understanding of the limitations and pitfalls of human cognition generally, particularly the biases in perception and judgment that we are all subject to by virtue of our species' neurocognitive architecture. Such biases include the Fundamental Attribution Error, mentioned earlier, as well as the various heuristics, or cognitive shortcuts, identified by Daniel Kahneman [36] and others-limitations to which all humans are subject. And adequate metacognition also includes understanding of one's idiosyncratic or personal biases and limitations, and awareness of when and how these biases tend to be activated.

Failures of metacognition often play a key role in failed efforts to deal with intergroup conflicts. One such failure is blindness to the role of one's own group in causing the conflict. The status, position, and actions of one's own group are always a major factor in any conflict with another group, and people are often completely unaware of this fact. A prominent example is George W. Bush's (and many other Americans') blaming the 2001 terrorist attacks on the putative evil natures of the attackers and their supporters and failing to recognize the role that US military presence and actions, US economic policies, and US cultural imperialism played in fomenting resentment, anger, and hatred toward the US in this group. The same failure of metacognition coupled with faulty social cognition can be seen in Hillary Clinton's characterization of Trump supporters as a "basket of deplorables" - a monumentally unwise outburst that may well have cost her the 2016 US presidential election.

These two examples also embody another prominent deficiency in metacognition: our failure to recognize how our own self-esteem needs incline us to denigrate outgroups-a denigration which always also involves the Fundamental Attribution Error of placing the entire blame for the outgroup's bad behavior or character on the group itself and failing to recognize the role played by external causes, including the attitudes and actions of one's own group. Bush's characterization of the 2001 attackers and their supporters as evil people who hate our freedoms, and Americans as peaceful, freedom-loving people, evinced, and helped to maintain, a profound blindness to his and America's own callous and even brutal impulses and actions (products of the ego-system), which mirrored an equally profound deficiency of social cognition in the failure to recognize the attackers' universally human needs, motives, and actions. Adequate metacognition would have revealed to Bush that his view of ingroup versus outgroup was a mirror image of the attackers' view, and that both "We're good, they're evil" positions were motivated by the same universal human need to maintain self-esteem, a sense of self-worth. Similarly, adequate metacognition would have provided Clinton with the awareness of her (universally human) need to self-enhance, her (universally human) tendency to do so by putting others down, often by engaging in projection and stereotyping, and her (universally human) proneness to the Fundamental Attribution Error of blaming others for their behavior, character, and life outcomes while ignoring the root causes of these, and her (universally human) susceptibility to avoid feeling guilty by denying the ways that her own attitudes, wealth, and position were contributing to the resentment that motivated many of Trump's supporters.

This same basic impulse to maintain or enhance one's own self-esteem, or sense of self-worth, motivates not only other verbal put-downs and cultural denigrations (e.g., stereotyping) of outgroups but also the choice of punitive rather than preventive or rehabilitative policies for all sorts of offenders and derelicts, including the poor, the homeless, the unemployed, substance abusers, criminals, and terrorists [26]. The same is true of most other policy decisions, both foreign and domestic. These suboptimal policies could be prevented by an adequate metacognition-one that understood, recognized, and interrupted these self-enhancement efforts and directed the search for self-enhancement onto more productive paths, such as those (motivated by the neuro-cognitive eco-system) that lead to building bridges rather than widening the chasms between one's own group and outgroups. 
Awareness of our dependence on others should include recognition of the fact that others made us who and what we are. Systems thinking leads us to recognize that we are not the causes of ourselves, or the sole cause of our survival: there is no such thing as a self-made person, or a self-sufficient person, or a self-reliant person. This means that, just as other people cannot legitimately be blamed (or credited), ultimately, for what they are or do, neither can we. Awareness of this fact results in humility and gratitude, and in compassion for both oneself and others - qualities that some wisdom scholars [1,17] have claimed as components of wisdom, and which are products (and also ancillaries) of rigorous systems thinking and awareness. Thus, just as the social cognition of the fact that others are constructed by forces beyond their control leads to compassion for them, so too the metacognitive awareness of our own constructed nature leads to self-compassion, recognition and acceptance of our flaws and shortcomings without engaging in self-hatred or self-blame. And it also leads to humility - rather than pride, arrogance, or complacency-and to gratitude and a desire to help others, who are, after all, neurologically, ontologically, existentially, and contingently part of oneself. Adequate causal/systems understanding is thus essential for adequate metacognition as well as for adequate social cognition.

\section{A Wisdom/Systems-Thinking Model}

Wisdom thus requires, as indicated in the figure below, taking comprehensive account of (1) the causes of a problem and (2) the likely consequences of the various possible responses to the problem. Executing these two key wisdom-constituting functions usually also requires taking adequate account of (3) the needs, motives, and behaviors of other people and (4) one's own psychological needs, motives, and limitations. Together these four cognitive functions form the core of systems thinking, which is increasingly necessary for solving the world's most complex problems, including "reducing hunger, poverty, and inequalities", providing "better access to clean water and education", and developing "better infrastructure, responsible consumption, and clean affordable energy" [24] (p. 368). Indeed, "most of the pressing problems facing human societies today cannot be addressed properly until a new generation of leaders familiar with system dynamics takes leadership roles" [23] (p. 65).

\section{How to Educate for Wisdom: Training in Systems Thinking}

The development of wisdom thus requires enhancing the capabilities and habits of performing these four functions when dealing with personal or social issues. That is, the cultivation of wisdom will involve enhancing one's ability to take more comprehensive cognizance of the causes of present issues and the likely consequences of possible responses to these issues - shown along the horizontal axis of Figure 1-and to more fully grasp the depths and complexities of both oneself and others, as indicated along the vertical axis of the diagram.

\subsection{Systems-Thinking Expertise Is Developed through Guided Practice}

How, then, can these four wisdom-constituting capabilities be most effectively developed? To answer this question, it is useful to begin with the recognition that, as we noted above, these four capabilities are cognitive skills of the sort that constitute expertise. This suggests that they will be most effectively developed by the same means that other forms of expertise are developed. And the most fundamental way in which expertise is developed is through what expertise researcher Anders Ericsson calls "deliberate practice" - practice in attending to, perceiving, assessing, and responding to the field of one's aspired expertise [37].

Mere practice, of course, as the saying goes, does not make perfect; it makes permanent. Simply repeating ineffective moves over and over again will not improve one's performance; it will only make it automatic and thus all the harder to improve. To result in improvement, practice must be accompanied by the detection and correction of errors. In the case of wisdom development, these include errors of attention (e.g., inadequate 
attention to critical causes of a situation), errors of perception (e.g., failing to detect critical cause-effect relationships), errors of assessment (e.g., underestimating or overestimating the impact of certain factors), and/or errors of response (e.g., inadequately counteracting harmful causes or supporting beneficial ones). Such error-detection and correction often proceed automatically, as a result of the feedback we get from reality itself when our actions fail to achieve the results we anticipate. But the process of error-detection and correction can be significantly enhanced by guided practice- that is, by coaching — which monitors the learner's performance, points out suboptimal elements of the performance, and offers instrutions, and in some cases exercises, for improving those elements [37] (pp. 98-100).

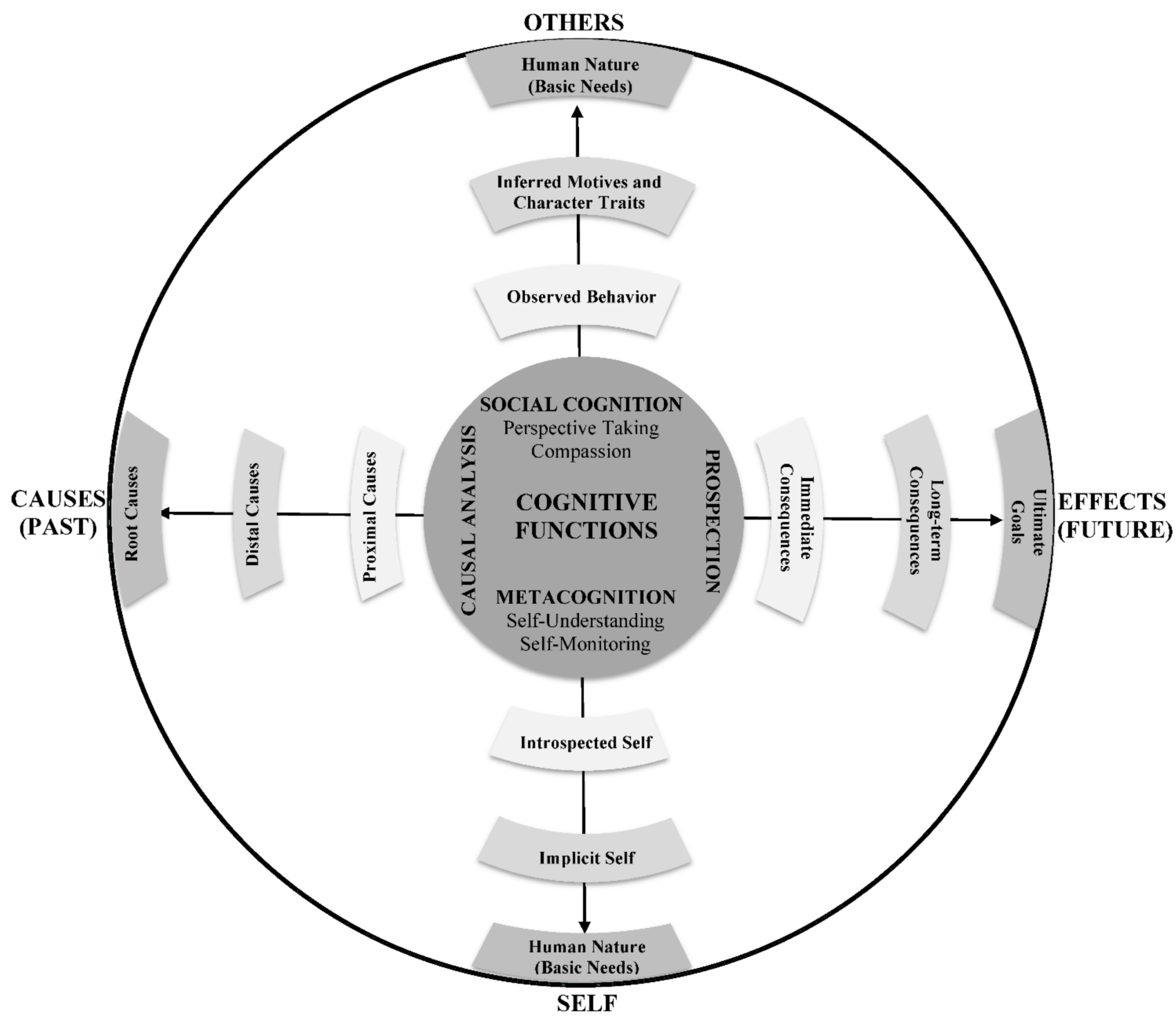

Figure 1. Field/Procedural Model of Wisdom/Systems Thinking.

\subsection{Cognitive Models of Causality as the Basis of Wisdom/Systems-Thinking}

The basic way in which deliberate practice produces expertise is by constructing cognitive models, or what Ericsson calls "mental representations". "The key change that occurs in our adaptable brains in response to deliberate practice", Ericsson explains, "is the development of better mental representations, which in turn open up new possibilities for improved performance" [37] (p. 75). The models that form the basis of expertise are of two types $[25,38]$. The first is a model of the system (including all its subsystems) constituting the field of expertise. Expertise in chess, for example, requires a cognitive model of the 
chess pieces, the chessboard positions, and all the relationships among them. The second type of model is a procedural model: a model of all the possible actions one can take in the system, and of which actions in various different situations are optimal for navigating the field to reach one's goal. In chess, this model includes the rules of the game and the most effective and least effective moves to make in response to certain patterns of chess pieces on the board.

Individuals with the greatest expertise in a domain are those with the best models of the field and of optimal pathways through the field to the goal. Elite athletes, for example, "appear to differ from merely excellent athletes not in the speed of their reflexes, ability to jump, or degree of training of basic motor patterns", but rather in their possession of "more detailed and accurate models of complex movements [i.e., procedural models] and competitive situations [i.e., field models]" [39] (p. 71). In order to optimally regulate behavior in a given environment, the human brain "must build an internal model of the system as a whole and make its decisions by consulting this model to understand how its actions will affect its world and itself" [39] (p. 66; emphasis in original). Such models are, at bottom, "structural models of causal relationships": they "ma[p] out which causes lead to which effects, with what reliability, and with what implications for ... achieving [one's] goals or risking [one's] neck. And ... prominent among the causes represented in the model will be the array of possible actions [one] might take, and prominent among the effects will be the likely outcomes of those actions" [40] (pp. 16, 17).

Such cause-effect models constitute the basis for each of the four wisdom-constituting cognitive capabilities described above. They are obviously crucial for understanding the complex network of direct and indirect, proximal, distal, and root causes of problems, which, as we have noted, is the first step of wise decision-making. And they are also necessary for prospection and strategic planning, which involves the mapping out of the various possible courses of action and their respective likely consequences. As Railton notes, a cause-effect model of a system functions as both a "forward model", enabling one to foresee both the direct and the indirect long-term and short-term consequences of any action one might take, and an "inverse model", which enables one to start from a distant goal and work backwards to determine the actions that will effect the achievement of that goal $[39,40]$. Prospection works in one or both of these ways. When we identify a possible intervention to counteract the cause of a problem, prospection then uses a "forward model" to identify the various downstream consequences of the intervention. And when we ask what needs to happen in order to reach a particular goal, we use an "inverse model" to identify the course(s) of action that will be necessary upstream to produce the desired state of affairs.

Cause-effect models are also the basis of social cognition [39]. The Fundamental Attribution Error is the result of a faulty cause-effect model of people in general: it is a model that omits, or gives insufficient weight to, causes of behavior and character that are beyond an individual's control. This faulty cause-effect model is embodied in many negative stereotypes, where they lead us to unjustifiably blame or credit various groups of people for behaviors, character traits, and life outcomes that are caused by factors beyond their control [41,42].

Metacognition is also based on cause-effect models-specifically, causes (internal and external) and consequences (internal and external) of the various types of cognitive error or deficiency to which we are prone. Metacognition works by comparing one's own cognitive performance with a model of optimal cognitive procedure and its (beneficial) consequences and / or a model of cognitive errors and their (negative) consequences [37]. The shaded inner circle of the wisdom/systems-thinking diagram in Figure 1 is such a model: it is an explicit graphic representation of the basic cognitive processes one needs to enact in relation to basic features of the world (i.e., cause-and-effect relationships) in order to produce the sorts of wise decisions necessary for solving major global problems.

The key to developing wisdom, then, is to form detailed, accurate, and comprehensive cognitive cause-and-effect models of how the world works. Indeed, as Peter Railton 
observes, "expertise is knowledge or wisdom, but in the concrete form of patterns stored in memory, accessible on cue by well-trained recognitional abilities" [39] (p. 48). These "patterns stored in memory" that enable wisdom are cause-and-effect models of how the world works, and wise decisions, or "optimal behavioral responses" to a situation, are achieved by using these models to determine which course of action has the best cost/benefit ratio [39] (p. 48). As the systems thinking expert and advocate Piero Mella observes, "Understanding the world means in fact being able to construct coherent and meaningful models" [25] (p. 2). Joe Tranquillo, another systems-thinking expert, explains: "A unifying methodology across all ways of knowing is the creation of models. A historian constructs a model when they tell a story that weaves together various facts. A politician debates another politician by arguing that they have a better model of how the world works and therefore know what to do to solve its problems" [24] (p. 17). Unfortunately, as a third systems-thinking expert, Asish Ghosh, points out, "These models need to be realistic and detailed enough to help us understand the problems and find their solutions [and] we frequently fail to create a model that is accurate enough" [23] (p. 185). "People in general", he notes, "and particularly those in power, such a politicians and legislators, often make decisions based on simple mental models, which often lead to unintended consequences or even major disasters" (p. 92). Mella makes the same basic point, observing that "our inability to dominate the world around us often is due to a lack of adequate model" [25] (p. 29).

\subsection{How to Develop Cognitive Models of Causality}

The construction of cause-effect models is the foundation of all learning [39] and is arguably the fundamental activity of the human brain, operating even at the level of perception [43]. It is a natural and automatic function of the mammalian brain: there is evidence that very young children construct such models, and that rats and other mammals do as well $[23,39,40]$. As Railton reports, "The brains of intelligent animals and humans respond to experience by forming expectations not only about individual events, but about higher-order regularities and types of events and outcomes, thus creating causal-explanatory models of the world much as a scientist does" [39] (p. 63; emphasis in original).

While such learning/model-construction proceeds automatically, informally, and largely unconsciously on the basis of experience, it can also occur, and be enhanced, through formal, supervised learning [39] — that is, by guided practice, or coaching. And in addition to direct personal experience, such learning can include observational learning and simulation. Indeed, optimal functioning in the world requires the ability to learn from more than just one's personal experience. Hence, social, observational learning is crucial for humans: learning about cause-effect relationships by observing, or hearing (or reading) about, the actions of others and the consequences of those actions $[39,40]$. In fact, the construction of causal models through social learning might be said to constitute the core of culture in general, and the development of such causal models is the fundamental aim of the entire scientific enterprise, and of much formal education. Culture, science, and formal education function as extensions of the automatic, unconscious causal-model building that the brain automatically engages in.

A more detailed understanding of how this learning/model-building process works can thus be a valuable resource for the development of an effective wisdom pedagogy. Such model-building occurs through the detection and correction of errors in prediction that result from models that are not completely adequate to reality. All our actions-and our perceptions as well, according to some cognitive scientists [44] - are based on what our (implicit or explicit) models of the world lead us to expect or predict their outcome will be. When our actions (or perceptions) are followed by the expected result, our model of the world is confirmed and reinforced. But when an action (or perception) fails to produce the expected result, our model is revised to accommodate the actual result of the action (or perception). The process begins with the (cause-effect) model, which leads us to expect that a certain action (cause) will produce a certain result (effect). We then execute the action 
and observe its results. If there is a discrepancy between our expectation and the observed consequences, our model is revised to account for the unexpected consequences, and the cycle is repeated, with the revised model leading to a revised expectation and/or a revised action, and so on. This iterative learning process can be modeled as shown in Figure 2 (based on [39], p. 62).

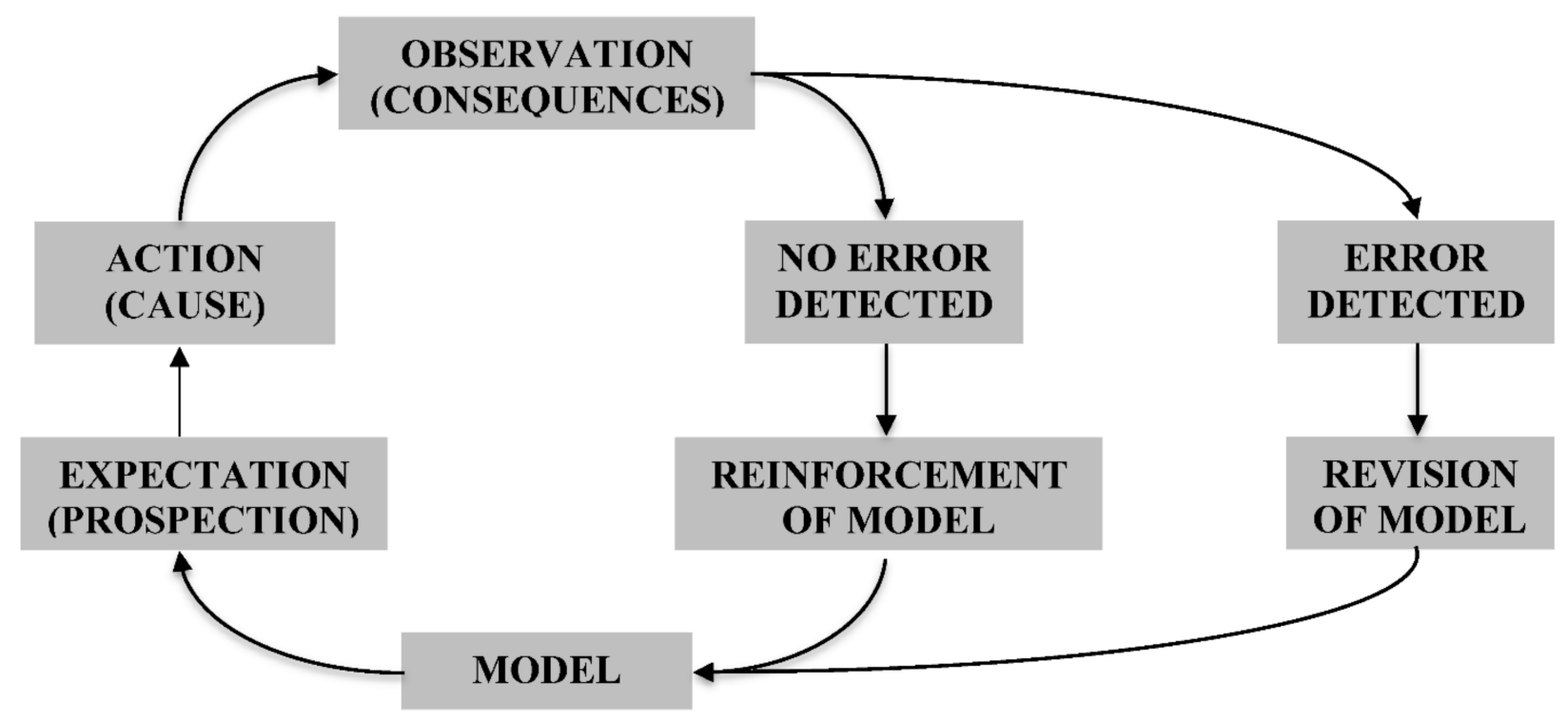

Figure 2. Learning as Error-Detection and Model-Revision.

These causal models are thus generalizations derived from the averaging of multiple experiences, common denominators found in numerous examples of a phenomenon encountered in variegated contexts. These models are not derived from, or profoundly altered by, single experiences, with certain important exceptions such as traumas and epiphanies. Multiple experiences spaced out over time are often required in order for the model to become adequate to the phenomenon it is mapping. This is because (1) each particular experience of the model's inadequacy produces an incremental rather than wholesale adjustment in the model, and also because (2) a certain period of time is required for each experience to be, as it were, averaged into the running total. The key to developing accurate cause-effect models is thus multiple encounters with a wide variety of examples in varying contexts, spread out over a period of days, months, or even years.

This model-development process has itself been explicitly modeled in the Complementary Learning Systems (CLS) model $[43,45,46]$. According to the CLS model, learningwhich is, at base, the construction of causal models of the world-proceeds through an ongoing interchange between two fundamental learning systems. The first is a high-fidelity surface system, located in the hippocampus, which keeps detailed records of individual experiences. Episodic memories are conscious instances of such records. The second learning system is a deep system, located in the neocortex, that produces the models by extracting common patterns from the episodic memories supplied (primarily during daydreaming and sleep, it is thought) by the high-fidelity surface system $[43,46])$. Chandra Sripada suggests that there are actually multiple deep learning systems of this sort, including statistical, causal, analogical, and social cognition systems, each of which constructs models by identifying deeper, hidden patterns in the specific examples (episodic memories) provided by the surface system [46].

Optimal learning thus requires the repeated encounter with a large number of examples that have varying features and occur in different contexts, and all of which embody the same deep, hidden patterns. "For the deep system to work", Sripada emphasizes, "it needs to be presented with a large number of examples" [46] (pp. 106, 107). In the informal learning that occurs from personal experience, these examples are supplied by 
one's episodic memories, which the brain often repeatedly rehearses, both as conscious, holistic memories and also, in all likelihood, in the components of these memories that reappear in fragmented form in dreams as well as in waking fantasies and imagination [43]. As Sripada points out, the learning of abstract patterns is significantly enhanced not only by this repeated rehearsal of memories but also by imagining possible events and thereby increasing the number of examples in the learning set [46].

\subsection{How to Provide Systems-Thinking Training in the Disciplines}

From this understanding, it follows that educating for the sort of wisdom needed to solve the world's most pressing problems must develop the most accurate and comprehensive field and procedural models possible. Fortunately, higher education in virtually all disciplines involves the construction of both types of models. As Ghosh states, "Our educational system, both formal and informal, is geared toward the ability to create sophisticated models quickly and efficiently" [23] (p. 91). Teaching involves helping students develop cognitive models-implicit if not explicit-both of the systems constituting each discipline's subject matter and of the procedures by which the discipline operates. Virtually all disciplines therefore have the potential to play a significant role in the development of systems thinking as a basis for solving the major problems confronting humanity.

Currently, however, this systems-thinking training is largely implicit rather than explicit, and it is limited to the specific domain of each academic discipline's subject matter. Consequently, the systems-thinking skills that students develop in the academic disciplines largely fail to transfer even to other academic disciplines [47], much less to their personal, professional, or civic lives outside the disciplines. What is needed to develop students systems thinking, and hence their wisdom, are pedagogies that not only train them in causal analysis/system-mapping, prospection/strategic planning, social cognition, and metacognition but also help them understand the discipline-specific versions of these skills as particular instances of more general, systems-thinking skills, and to recognize how these skills are essential, and transferable, to their personal, professional, and civic life beyond the academy $[25,47]$.

Training a citizenry capable of solving global problems can be advanced by making this fact explicit and emphasizing it-in the way that Fritjof Capra and Pier Luigi Luisi, in The Systems View of Life [48], do for disciplines ranging from physics to chemistry to biology to psychology to sociology to religion/spirituality, showing how all phenomena, from atoms to human life and its products are systems (and actually systems within systems [21]). As Perkins and Salomon advise, "teachers can point out explicitly the more general principles behind particular skills or knowledge or, better, provoke students to attempt such generalizations themselves". In this way, "teachers can directly teach problem-solving ... and provoke broad-spectrum practice reaching beyond their own subject matters" [47] (pp. 28, 29).

In addition to emphasizing the systems nature and causal relations constituting a discipline's subject matter, individual courses should also make explicit the roles of causal analysis, prospection, social cognition, and metacognition in the various practices of their respective disciplines. This involves framing and teaching disciplinary practices ranging from the design of experiments and the analysis of their results to the analysis of historical events, literary texts, or works of art in terms of causal analysis, prospection, social cognition, and/or metacognition. Different disciplines, of course, involve these four functions in different ways and to different degrees, and some courses may not involve all of them, but all courses involve at least one, and many involve them all.

The optimal way to develop systems-thinking expertise in the university is to introduce students to systems thinking and its components early in their university experience and then engage them in repeatedly exercising the four cognitive functions and performing systems thinking in courses in multiple disciplines throughout the remainder of their college education. The basic pedagogical strategy is to engage students in repeatedly performing and reviewing each of the four systems-thinking functions, while exercising 
metacognitive awareness of what cognitive function they are performing, why it is important, and what its optimal performance involves. General pedagogical practices to implement this strategy include the following basic steps.

\subsection{Principles of Systems-Thinking Pedagogies}

1. Explaining and demonstrating the nature of systems. This involves identifying and explaining to students the systems constituting, and the systemic nature of, each discipline's subject matter, framing the subject matter of one's own discipline as a system, and as itself composed of systems and embedded in other systems. Examples of systems in the physical sciences include atoms, molecules, cells, organs, organisms, ecosystems, planets, and galaxies. In the human sciences minds, families, institutions, organizations, cultures, and societies are all systems. And languages, texts, narratives, and ideologies are crucial systems studied in the humanities, as are media, forms, schools, and artifacts in the arts. Framing each topic or element of a discipline's subject matter in terms of the system(s) in which it operates helps students understand the nature of systems in general, developing their general cognitive model of systems by repeatedly taking a systems perspective on the subject matter and by seeing the particular systems they are learning about in any given course as instances of systems in general.

2. Explaining and demonstrating the nature and importance of systems thinking, including the roles that the four key cognitive functions play in the various analytic, interpretive, and research practices of the discipline, and what happens when one of these cognitive functions is not adequately performed. Explaining and repeatedly framing the activities of the discipline as instances of systems thinking - that is, as instances of causal analysis/system mapping, prospection/strategic planning, social cognition, and metacognition-enhances the capability and habit of performing these key functions by developing more precise and detailed procedural models of them.

A. Examples of causal analysis/systems mapping in the sciences include interpreting the results of lab experiments and field studies (which focuses on independent variables as causes and dependent variables as effects), diagnosing physical and mental illnesses, and identifying the causes of social conflicts and economic problems. Examples of causal analysis in the humanities include identifying the multiple causes of historical events or of the actions of literary characters.

B. Prospection/strategic planning is present in all types of design, including fashion, architectural, engineering, technological, environmental, urban, and interior [21]. Prospection in the sciences is central to formulating hypotheses, designing experiments, and articulating future directions for research, and it is at the core of environmental impact assessments in biology and devising treatments for physical and mental problems in the health sciences. In the humanities, prospection is operative not only in writing and reading futuristic narratives in literature or performing thought experiments in philosophy, but also in virtually every act of reading, where one is always anticipating how a sentence will end or how an argument or narrative will unfold [49,50], and in writing, when one prospects how one's audience will respond to specific words or arguments.

C. Social cognition is crucial in designing experiments in psychology and studies in sociology, which requires knowledge of how people tend to respond to certain kinds of situations and stimuli. It is also essential for explaining the behavior of real and fictional individuals and groups when studying history, literature, or philosophy. And it is present whenever one considers how one's audience is likely to respond to one's argument or work of art, including when students imagine how their instructors are likely to judge their papers.

D. Metacognition is also ubiquitous across the academic disciplines: it is present whenever one monitors one's adherence to disciplinary protocols, procedures, and standards in designing, conducting, and interpreting the results of scientific studies or in writing 
a paper, and whenever one reflects on and analyzes one's cognitive or emotional responses to a narrative or a work of art.

3. Engaging students in repeated guided practice, with feedback, of each of four cognitive functions of systems thinking. Most importantly, instruction in each discipline should include readings, discussions, research tasks, writing assignments, and exams that repeatedly engage students in practicing each of the four cognitive functions constituting systems thinking. To maximize generalization and transfer, instruction should repeatedly (a) frame these activities in terms of these cognitive functions, (b) emphasize their role and importance both within the discipline and beyond, and (c) explain how the capabilities for adequately performing these functions are developed through repeated guided practice, as in apprenticeship and coaching [37], just as skill in playing a musical instrument or a sport is.

A. Causal analysis/systems mapping. Practice in causal analysis can be activated by reading directives that prime students to identify, map, and encode in memory important causal relationships that constitute, impact, and/or are affected by the phenomena they read about, including causal networks involved in physical and chemical reactions or biological processes; changes in climate, weather, ecosystems, or the economy; and the behaviors of individuals and groups in history and literature. Such practice can also be provided by assignments to construct diagrams of causal relations [51], from structural equation modeling in the sciences to identifying the complex networks of causes of human behavior, social conflicts, and social change in the social sciences and humanities. Evaluating the adequacy of various examples of causal analysis, and noting especially the harmful consequences of the failure to identify key causes of a problem, are also quite useful in developing adequate procedural models of system mapping that include searching for multiple proximal causes, enabling and disabling causes, temporally distant causes, and root, systemic causes.

B. Prospection/strategic planning. Students can be engaged in the practice of prospection by design tasks of all types-buildings, spaces, clothes, a work of art, a scientific experiment, or a lesson plan-that require them to identify their various design options and consider the respective effects, both intended and unintended, short-term and long-term, that each option might have on each affected party. Prospection can be developed through other types of future-thinking as well, such as asking students to describe or narrate what they think will happen in the future for fictional characters or real people-individuals, groups, nations, the planet-and explain how these outcomes are likely to be caused. And prospection practice can also be elicited by having students evaluate historical or literary examples of prospection and explain the nature and respective consequences of the various instances of adequate and inadequate prospection.

C. Social cognition. Social cognition can be practiced by identifying the multiple layers of causes of the actions, intentions, or character of either fictional or real people, including literary characters, historical personages, or experimental subjects, or the likely consequences of certain interventions, events, or policies for people, including the responses of fictional or historical people to counterfactual events, the responses of experimental subjects to various situational factors, the responses of readers to an argumentative essay, and so on.

D. Metacognition. Students' metacognition can be exercised and developed by assignments that repeatedly engage them in attending to and assessing their performance of the four cognitive functions, including repeatedly reflecting on and understanding what the adequate performance of these cognitive functions involves and where the major challenges and pitfalls lie. Students in humanities classes can be instructed, for example, to first describe their feelings and moral judgments about literary characters or historical personages and then assess what these responses reveal about themselves-their biases, values, fears, desires, and so on. Social science classes can engage students in practicing vigilance to avoid various cognitive biases such as the 
fundamental attribution error and spontaneous trait inference, and courses in the physical sciences can train students to be alert to their inclination to make common errors in probabilistic reasoning.

\section{Conclusions}

In order to develop the sort of wisdom necessary for solving humanity's most pressing problems, then, instruction in the academic disciplines in the university should include explanations of (a) the nature of complex systems, (b) the systems nature of the discipline's subject matter, (c) the nature and importance of the four systems-thinking skills, and (d) the role of these four skills in the discipline's practices. In addition, and most crucially, (e) assignments and activities in university courses should engage students in repeated practice of these four key cognitive functions; (f) explanations should be given for how each assignment exercises and trains these skills; and (g) it should be constantly emphasized and demonstrated that these key skills can and should transfer to other disciplines and, more importantly, to solving major global problems, including climate change, environmental degradation, disease, intergroup conflicts, crime, violence, poverty, inequality, ethnocentrism, and authoritarianism. If students can be explicitly trained in the basics of systems, and of systems thinking and its components, early in their college experience, and then have the specific subject matters and the disciplines of exploring and operating with these systems framed in terms of systems and systems thinking in other courses throughout their university education, the habit and capabilities of systems thinking will develop beyond a mere collection of largely implicit and discrete discipline-specific practices and skills into the more general mode of problem-solving and decision-making that is essential for effectively addressing humanity's major problems and for living a responsible, productive, and fulfilling life on this planet.

Funding: This research received no external funding.

Institutional Review Board Statement: Not applicable.

Informed Consent Statement: Not applicable.

Data Availability Statement: Not applicable.

Acknowledgments: Thanks to the Kent State University Research Council for providing support for researching and writing this article.

Conflicts of Interest: The author declares no conflict of interest.

\section{References}

1. Ardelt, M. Wisdom and Well-Being. In The Cambridge Handbook of Wisdom; Sternberg, R.J., Glück, J., Eds.; Cambridge University Press: New York, NY, USA, 2019; pp. 602-625.

2. Thornton, S. Ideas for Teaching Wisdom, 2nd ed.; MA Education Ltd.: London, UK, 2017. Available online: https: / www.sec-ed.co. uk/best-practice/ideas-for-teaching-wisdom/ (accessed on 10 November 2019).

3. Sternberg, R.J.; Reznitskaya, A.; Jarvin, L. Teaching for Wisdom: What Matters Is Not Just What Students Know, But How They Use It. Lond. Rev. Educ. 2007, 5, 143-158. [CrossRef]

4. Maxwell, N. The Urgent Need for Social Wisdom. In The Cambridge Handbook of Wisdom; Sternberg, R.J., Glück, J., Eds.; Cambridge University Press: New York, NY, USA, 2019; pp. 754-780.

5. Sloman, S. Causal Models: How People Think about the World and Its Alternatives; Oxford University Press: New York, NY, USA, 2005.

6. Sternberg, R.J.; Emily, S.H. Teaching for Wisdom. In The Cambridge Handbook of Wisdom; Sternberg, R.J., Glück, J., Eds.; Cambridge University Press: New York, NY, USA, 2019; pp. 372-406.

7. Starr, P. 4 Strategies for Teaching Wisdom Today; Inside Higher Ed: Washington, DC, USA, 2018. Available online: https://www. insidehighered.com/users/peter-starr (accessed on 10 November 2019).

8. Swartwood, J. Wisdom as an Expert Skill. Ethical Theory Moral Pract. 2013, 16, 511-528. [CrossRef]

9. Ferrari, M.; Kim, J. Educating for Wisdom. In The Cambridge Handbook of Wisdom; Sternberg, R.J., Glück, J., Eds.; Cambridge University Press: New York, NY, USA, 2019; pp. 347-371.

10. Bruya, B.; Ardelt, M. Fostering Wisdom in the Classroom, Part 1: A General Theory of Wisdom Pedagogy. Teach. Philos. 2018, 41, 239-253. [CrossRef] 
11. Staudinger, U.M. The Distinction between Personal and General Wisdom: How Far Have We Come? In The Cambridge Handbook of Wisdom; Sternberg, R.J., Glück, J., Eds.; Cambridge University Press: New York, NY, USA, 2019; pp. $182-201$.

12. Bruya, B.; Ardelt, M. Wisdom Can Be Taught: A Proof-of-Concept Study for Fostering Wisdom in the Classroom. Learn. Instr. 2018, 58, 106-114. [CrossRef]

13. Sternberg, R.J. What Is Wisdom and How Can We Develop It? Ann. Am. Acad. Political Soc. Sci. 2004, 591, 164-174. [CrossRef]

14. Sternberg, R.J. Why the World is Falling Apart: The (Non)Place of Wisdom in Today's World; Presented at the Center for Practical Wisdom Research Forum; Chicago, IL, USA, 2016.

15. Bangen, J.K.; Meeks, T.W.; Dilip, V.J. Defining and Assessing Wisdom: A Review of the Literature. Am. Geriatr. Psychiatry 2013, 21, 1254-1266. [CrossRef] [PubMed]

16. Grossman, I. Wisdom and How To Cultivate It: Review of Emerging Evidence for a Constructivist Model of Wise Thinking. Eur. Psychol. 2017, 22, 233-246. [CrossRef]

17. Santos, C.H.; Alex, H.C.; Grossmann, I. Wisdom in a Complex World: A Situated Account of Wise Reasoning and its Development. Soc. Pers. Psychol. Compass 2017, 11,1-13. [CrossRef]

18. Sloman, S.; Fernbach, P. The Knowledge Illusion; Penguin Random House: New York, NY, USA, 2017.

19. Meadows, D.H. Thinking in Systems; Chelsea Green: White River Junction, VT, USA, 2008.

20. Stroh, D.P. Systems Thinking for Social Change; Chelsea Green: White River Junction, VT, USA, 2015.

21. Boylston, S. Designing with Society: A Capabilities Approach to Design, Systems Thinking and Social Innovation; Routledge: New York, NY, USA, 2019.

22. Fieguth, P.A. Introduction to Complex. Systems: Society, Ecology, and Nonlinear Dynamics; Springer: Cham, Switzerland, 2017.

23. Ghosh, A. Dynamic Systems for Everyone: Understanding How Our World Works; Springer Nature: Cham, Switzerland, 2016.

24. Tranquillo, J.A. Introduction to Complex. Systems: Making Sense of a Changing World; Springer: Cham, Switzerland, 2019.

25. Mella, P. Systems Thinking: Intelligence in Action; Springer: New York, NY, USA, 2012.

26. Bracher, M. Social Symptoms of Identity Needs: Why We Have Failed to Solve Our Social Problems, and What to do about It; Karnac: London, UK, 2009.

27. Crocker, J.; Canevello, A. Consequences of Self-Image and Compassionate Goals. Adv. Exp. Soc. Psychol. 2012, 45, $229-277$.

28. Lama, D. What is important. Available online: https://www.optimize.me/quotes/dalai-lama/803153-what-is-important-is-thatwhen-pursuing-our-own-self-interest/ (accessed on 28 January 2020).

29. Senge, P.M. The Fifth Discipline, Revised ed.; Crown Business: New York, NY, USA, 2006.

30. Gill, M.J.; Cerce, S.C. He Never Willed to Have the Will He Has: Historicist Narratives, 'Civilized' Blame, and the Need to Distinguish Two Notions of Free Will. J. Personal. Soc. Psychol. 2017, 112, 361-382. [CrossRef] [PubMed]

31. Waller, B.N. Against Moral Responsibility; MIT Press: Cambridge, MA, USA, 2011.

32. Harris, S. Free Will; Free Press: New York, NY, USA, 2012.

33. Bracher, M.; Barnbaum, D.; Byron, M.; Clewell, T.; Docherty, N.; Massardier-Kenney, F.; Pereplyotchik, D.; Roxburgh, S.; SmithPryor, E. Compassion-Cultivating Pedagogy: Advancing Social Justice by Improving Social Cognition through Literary Study. Sci. Study Lit. 2019, 9, 107-162. [CrossRef]

34. Greene, J.; Cohen, J. For the Law, Neuroscience Changes Nothing and Everything. Philos. Trans. R. Soc. Lond. B Biol. Sci. 2004, 359, 1775-1785. [PubMed]

35. Wheatley, T. Neuroscience versus Phenomenology and the Implications for Justice. In The Moral Brain: An. Interdisciplinary Perspective; Decety, J., Wheatley, T., Eds.; MIT Press: Cambridge, MA, USA, 2015; pp. 267-278.

36. Kahneman, D. Thinking Fast and Slow; Farrar, Strauss and Giroux: New York, NY, USA, 2013.

37. Ericsson, A.; Poole, R. Peak: Secrets from the New Science of Expertise; Houghton Mifflin Harcourt: New York, NY, USA, 2016.

38. Sloman, S.A.; Hagmayer, Y. The Psychologic of Choice. Trends Cogn. Sci. 2006, 10, 407-412. [CrossRef] [PubMed]

39. Railton, P. Intuitive Guidance: Emotion, Information, and Experience. In Homo Prospectus; Seligman, M.E.P., Railton, P., Baumeister, R.F., Sripada, C., Eds.; Oxford University Press: New York, NY, USA, 2016; pp. 33-86.

40. Railton, P. Introduction. In Homo Prospectus; Seligman, M.E.P., Railton, P., Baumeister, R.F., Sripada, C., Eds.; Oxford University Press: New York, NY, USA, 2016; pp. 3-32.

41. Reyna, C.; Henry, P.J.; Korfmacher, W.; Tucker, A. Examining the Principles in Principled Conservatism: The Role of Responsibility Stereotypes as Cues for Deservingness in Racial Policy Decisions. J. Personal. Soc. Psychol. 2005, 90, 109-128. [CrossRef] [PubMed]

42. Wittenbrink, B.; Gist, P.; Hilton, J.L. Structural Properties of Stereotypic Knowledge and Their Influences on the Construal of Social Situations. J. Personal. Soc. Psychol. 1997, 72, 526-543. [CrossRef]

43. Kumaran, D.; Hassabis, D.; McClelland, J.L. What Learning Systems do Intelligent Agents Need? Complementary Learning Systems Theory Updated. Trends Cogn. Sci. 2016, 20, 512-534. [CrossRef] [PubMed]

44. Hohwy, J. The Predictive Mind; Oxford University Press: New York, NY, USA, 2013.

45. O'Reilly; Randall, C.; Bhattacharyya, R.; Howard, M.; Ketz, N. Complementary Learning Systems. Cogn. Sci. 2014, 38, 1229-1248. [CrossRef] [PubMed]

46. Sripada, C. Imaginative Guidance: A Mind Forever Wandering. In Homo Prospectus; Seligman, M.E.P., Railton, P., Baumeister, R.F., Sripada, C., Eds.; Oxford University Press: New York, NY, USA, 2016; pp. 103-132.

47. Perkins, D.N.; Salomon, G. Teaching for Transfer. Educ. Leadersh. 1988, 46, 22-32. Available online: https:/ /eric.ed.gov/?id=EJ376 242 (accessed on 28 January 2020). 
48. Capra, F.; Luisi, P.L. The Systems View of Life: A Unifying Vision; Cambridge University Press: New York, NY, USA, 2014.

49. Fish, S. Literature in the Reader: Affective Stylistics. New Lit. Hist. 1970, 2, 123-162. [CrossRef]

50. Iser, W. The Reading Process: A Phenomenological Approach. New Lit. Hist. 1972, 3, 279-299. [CrossRef]

51. Shapiro, B.P.; van den Broek, P.; Fletcher, C.R. Using Story-Based Causal Diagrams to Analyze Disagreements about Complex Events. Discourse Process. 1995, 20, 51-77. [CrossRef] 